\title{
A patient with spontaneous rupture of the esophagus and concomitant gastric cancer whose life was saved: case of report and review of the literature in Japan
}

Nobuhisa Matsuhashi ${ }^{1 *}$, Narutoshi Nagao ${ }^{1}$, Chihiro Tanaka', Takuo Nishina', Masahiko Kawai ${ }^{1}$, Katsuyuki Kunieda ${ }^{1}$ and Hitoshi Iwata ${ }^{2}$

\begin{abstract}
A 71-year-old man suddenly developed abdominal pain and vomiting on drinking soda after a meal, and visited a physician. Cervical subcutaneous and mediastinal emphysemas were observed on $\mathrm{CT}$, and the patient was transferred to the emergency medical center of our hospital on the same day. Esophagography was performed at our department. A ruptured region was identified on the left side of the lower thoracic esophagus, and surgery was emergently performed employing sequential left thoracoabdominal incision. The chest wall was adhered due to inflammation, and large amounts of residual food and sloughing were present in the thoracic cavity and mediastinum. Moreover, necrotic changes were noted in the superior through inferior mediastinum. An about 2$\mathrm{cm}$ rupture site was confirmed on the left side of the lower thoracic esophagus and closed by suture and filling with pediculate omentum. The presence of a tumorous lesion located mainly in the body of the stomach and lymph node enlargement were also diagnosed before surgery, for which gastric and intestinal fistulae were inserted to prepare for the second-stage surgery. The patient was admitted to an ICU after surgery. ARDS and MRSA-induced pneumonia and enteritis concomitantly developed but remitted. Curative surgery for gastric cancer was performed at $40 \mathrm{POD}$. Spontaneous rupture of the esophagus is relatively rare and that complicated by gastric caner is very rare, with only six cases being reported in Japan. Herein, we report the case.
\end{abstract}

Keywords: spontaneous rupture of the esophagus, gastric cancer, prediagnoisis

\section{Background}

Spontaneous rupture of the esophagus is rare, and the life-saving rate is still low. We encountered a very rare case in which rupture occurred due to concomitant gastric cancer. Only 6 cases including this patient have been reported in Japan, and this is the first case report in English. The disease could be preoperatively diagnosed, and the patient could be saved despite the condition being very serious. Herein, we report the case.

\section{Case presentation}

The patient was a 71-year-old male with a chief complaint of abdominal pain. There was no particular past

\footnotetext{
* Correspondence: nobuhisa517@hotmail.com

'Department of Surgery, 4-6-1 Noishiki, Gifu City 500-8717, Japan

Full list of author information is available at the end of the article
}

medical history. The patient suddenly developed abdominal pain and vomiting on drinking soda after a meal, and visited a physician. Cervical subcutaneous and mediastinal emphysemas were observed on $\mathrm{CT}$, and the patient was transferred to the emergency medical center of our hospital on the same day. On admission, the height was $168 \mathrm{~cm}$; body weight, $55 \mathrm{~kg}$; BP, 154/76 mmHg; HR, 93/min; respiratory rate, $35 / \mathrm{min}$; and SpO2, 98\% (O2 5 L mask). The patient could not hold a supine position due to respiratory distress and pain. On blood testing and chemistry on admission, WBC was $14.5 \times$ $10^{3} / \mathrm{ul}$ and CRP was $0.34 \mathrm{mg} / \mathrm{dl}$, showing high levels of inflammatory parameters. BUN was $46 \mathrm{mg} / \mathrm{dl}$ and $\mathrm{Cr}$ was $4.03 \mathrm{mg} / \mathrm{dl}$, revealing features of prerenal renal failure. PT-INR was 1.35; AT-III, 63\%; and FDP, $64 \mu \mathrm{g} / \mathrm{ml}$. CEA was $11.7 \mathrm{ng} / \mathrm{ml}$, showing a high level. 
On plain thoracoabdominal X-ray radiography, no apparent free air was present, but marked right pleural effusion was noted (Figure 1).

On thoracoabdominal CT, marked subcutaneous emphysema was present in the cervical region through the mediastinum, and pleural effusion was also observed (Figures 2). Moreover, the stomach was markedly dilated, and hypertrophy of the antral stomach wall and $15-\mathrm{mm}$ lymph node swelling around it were observed (Figure 3).

The ruptured site was identified on the left side of the lower thoracic esophagus on esophagography and diagnosed as spontaneous rupture of the esophagus. Surgery was emergently performed in consideration of concomitant gastric cancer.

The first surgery was performed employing sequential left thoracoabdominal incision. The chest wall was adhered due to inflammation, and large amounts of residual food and sloughing were present in the thoracic cavity and mediastinum (Figure 4). Moreover, necrotic changes were noted in the superior through inferior mediastinum. An about 2-cm rupture site was identified on the left side of the lower thoracic esophagus and closed by suture and filling with pediculate omentum. Necrotized substances were removed as much as possible, followed by massive irrigation. The presence of a tumorous lesion mainly in the body of the stomach and lymph node enlargement were also diagnosed before surgery, for which gastric and intestinal fistulae were inserted to prepare for the second-stage surgery (Figure 5).After surgery, the patient was admitted to an ICU, in

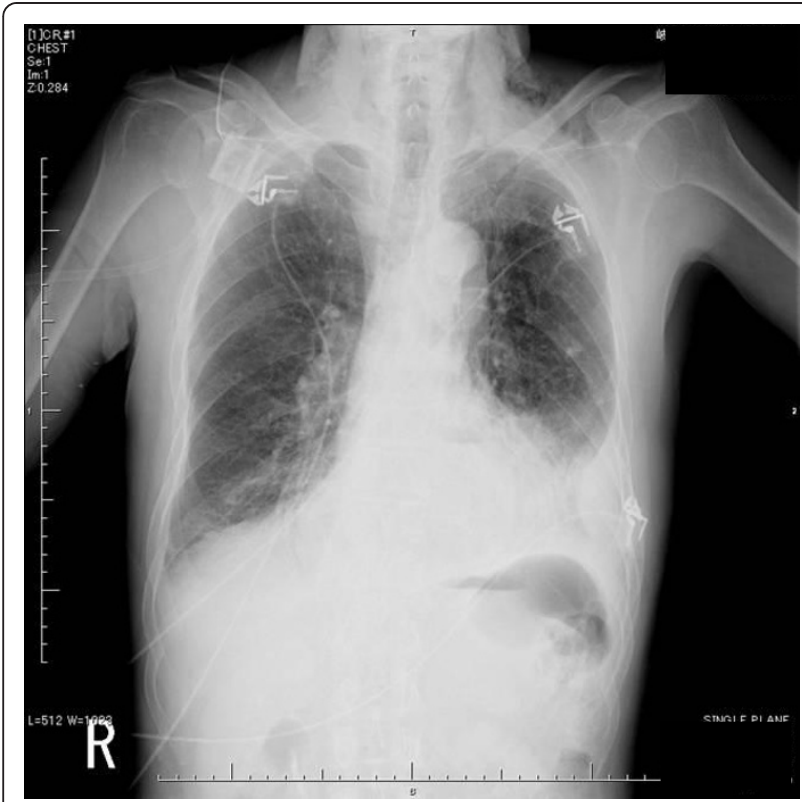

Figure 1 Plain chest X-ray radiography. No apparent free air was present, but marked right pleural effusion was observed.

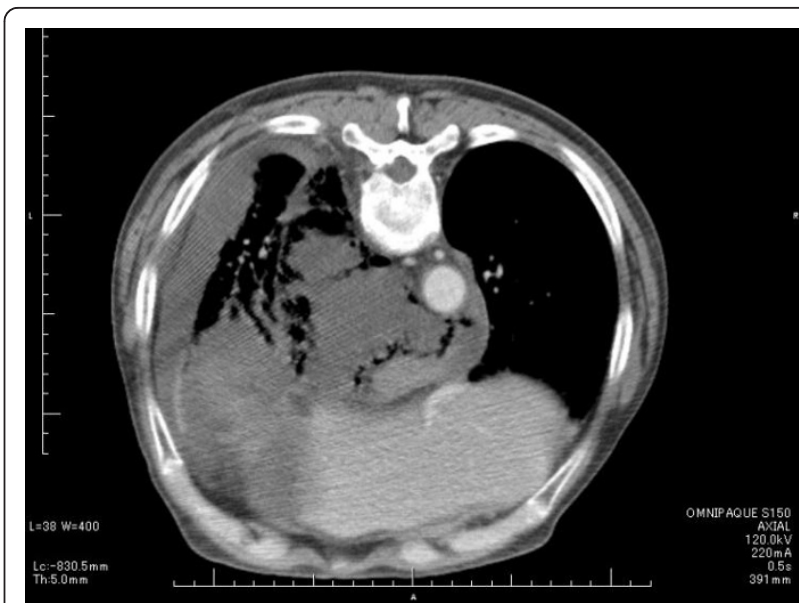

Figure $\mathbf{2}$ Chest CT. Large amounts of residual food and air were observed in the mediastinum, and pleural effusion was also present.

which concomitant ARDS and sepsis developed. Moreover, MRSA-induced pneumonia and enteritis also developed but remitted. Total gastrectomy + splenectomy + D2 lymphadenectomy could be performed at 40 POD after the first surgery. The final pathological diagnosis was pStageIV (TNM classification: T3N1M1) with por 2 and No. 10 lymph node metastasis (Japanese Classification of Gastric Carcinoma). The postoperative course was favorable, and the patient was alive as of 2 years after surgery.

\section{Discussion}

In spontaneous rupture of the esophagus, a sharp rise in intraesophageal pressure due to vomiting causes fullthickness (mucosa and muscle layer) rupture. Since the disease was initially reported by Boerhaave [1] of

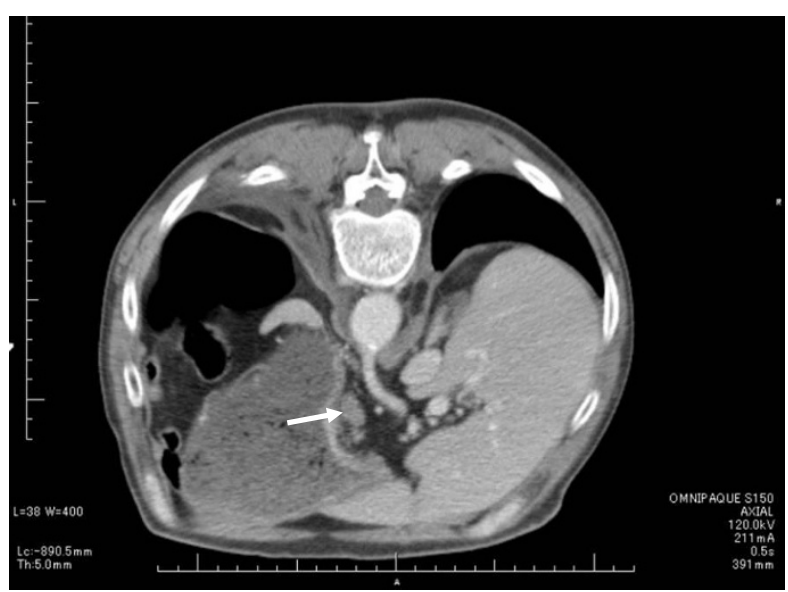

Figure 3 The stomach was markedly dilated. The stomach was markedly dilated, and hypertrophy of the antral stomach wall and 15-mm lymph node swelling around it were noted. 


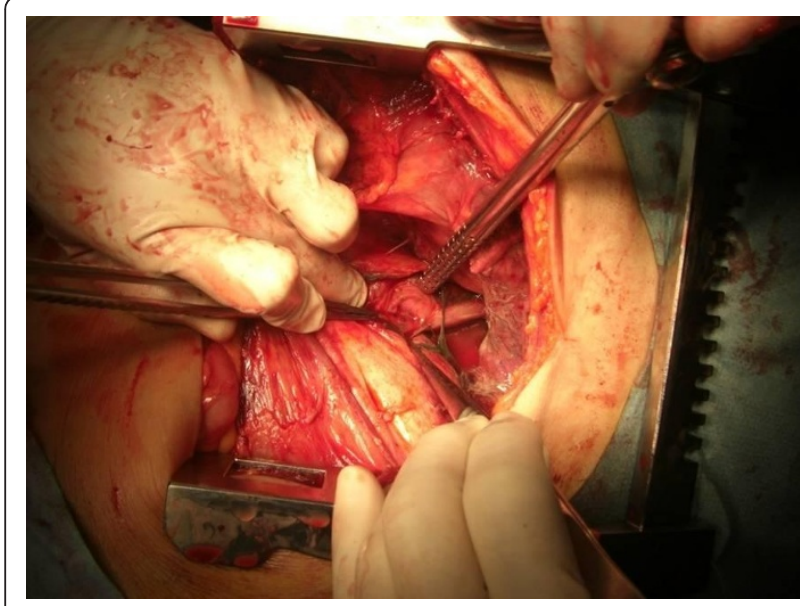

Figure 4 In surgery employing sequential left thoracoabdominal incision. In surgery employing sequential left thoracoabdominal incision, the chest wall was adhered due to inflammation, and large amounts of residual food and sloughing were present in the thoracic cavity and mediastinum. Necrotic changes were also noted in the superior through inferior mediastinum.

Holland in 1724, it is also called Boerhaave syndrome ${ }^{1)}$. In Japan, Yoshida et al. [2]reported it in 1935, and several cases have been reported thereafter. The mortality rate was higher than $40 \%$ and gradually decreased, but the outcomes of treatment are still unfavorable compared to other diseases, and the prognosis is particularly poor in patients brought to hospital in a state of shock.

There is a high incidence in men, accounting for $92 \%$ of all cases. The onset age peaks in the $40 \mathrm{~s}$, and

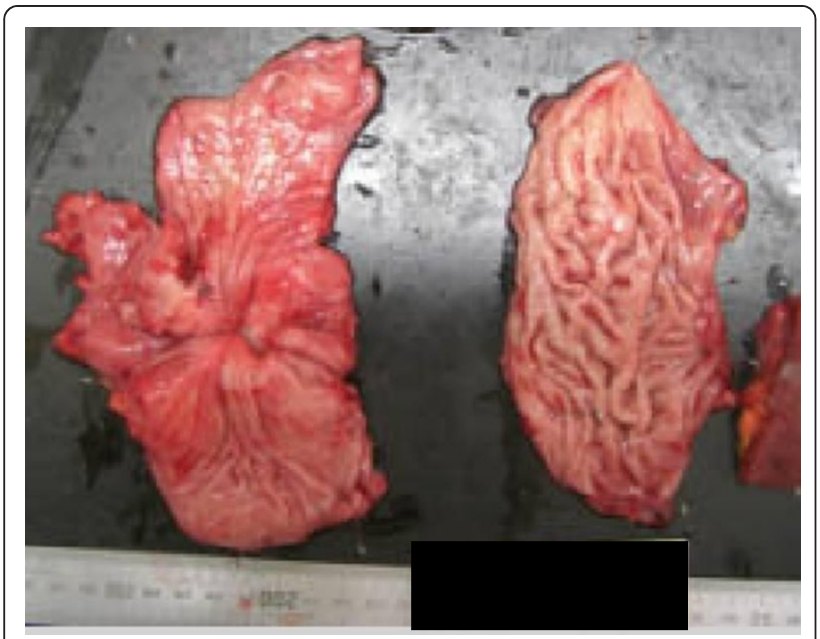

Figure 5 Total gastrectomy + splenectomy + D2 lymphadenectomy could be performed at 40 POD after the first surgery. The final pathological diagnosis was pStagelV (TNM classification: T3N1M1) with por 2 and No. 10 lymph node metastasis (Japanese Classification of Gastric Carcinoma). incidences at 30-59 years of age account for $73 \%$ of all cases. The rupture site was located in the lower esophagus in $84 \%$ and left wall in $67 \%$, and the most frequent inducer was vomiting (64\%) followed by other mechanical factors, such as overeating, cough, and trauma, accounting for 19\% [3].Regarding the diagnosis, awareness of this disease may lead to early diagnosis. Actually, only about $30 \%$ of cases were diagnosed as rupture of the esophagus. When it is suspected, esophagography is performed using an aqueous contrast medium, Gastrografin, and the disease is definitely diagnosed when leakage in the mediastinum or thoracic cavity is observed. As CT has recently spread, noninvasive CT may be useful, especially for patients in a state of shock. MDCT may also be useful for assistive diagnosis of the lesions.

For treatment, surgery and conservative treatment including thoracic cavity drainage are available, but surgical treatment may be the most appropriate [4]. Fukushima et al. reported that the mortality rates after surgical and conservative treatments were 7.7 and $50.0 \%$, respectively, showing unfavorable outcomes in the conservative treatment group [5].

It is still controversial whether laparotomic drainage alone in the mediastinum or thoracotomic drainage should be adopted [6-10].

In our patient, not only rupture of the esophagus but also hypertrophy of the antral stomach wall and lymph node swelling were observed on preoperative MDCT, for which sequential left thoracoabdominal incision (oblique incision) was selected. Gastric (to reduce pressure) and intestinal (for tube nutrition) fistulas were inserted, in addition to drainage, providing useful for postoperative enteric nutrition.

Of cases assumed to be induced by vomiting, duodenal ulcer was the most frequent cause, and gastric ulcer, postgastrectomy disorder, and congenital obstruction are included in the causes. In this patient, in addition to the underlying vulnerability of the esophageal wall and promotion of nausea and vomiting, the pylorus was obstructed by gastric cancer as a local factor of nausea and vomiting. Under these conditions, ingestion of the meal and soda may have rapidly elevated the inner pressure and caused rupture.

This is a valuable case: the 6th case of spontaneous rupture of the esophagus associated with concomitant gastric cancer in Japan [11-14], and the first report in English(Table 1). Since preoperative imaging diagnosis was possible, we report the case including CT and esophagography findings.

\section{Conclusion}

Spontaneous rupture of the esophagus associated with concomitant gastric cancer are rare.To our knowledge this is the first reported case. 
Table 1 Reported cases of Spontaneous rupture of the esophagus with gastric cancer in Japan

\begin{tabular}{llllllll}
\hline No & Author & Year & Age & Sex & $\begin{array}{l}\text { Gastric } \\
\text { Cancer }\end{array}$ & $\begin{array}{l}\text { Operative } \\
\text { method }\end{array}$ & Result \\
\hline 1 & Yoshila & 1981 & 61 & W & L,3type & $\begin{array}{l}\text { Distal } \\
\text { gastrectomy }\end{array}$ & better \\
\hline 2 & Kishina & 1987 & 53 & W & L,3type & $\begin{array}{l}\text { Distal } \\
\text { gastrectomy }\end{array}$ & better \\
\hline 3 & Itano & 1992 & 65 & W & W-L,2type & $\begin{array}{l}\text { Distal } \\
\text { gastrectomy }\end{array}$ & better \\
\hline 4 & Akioka & 1996 & 62 & W & $\begin{array}{l}\text { W,O-llc } \\
\text { type }\end{array}$ & $\begin{array}{l}\text { Distal } \\
\text { gastrectomy }\end{array}$ & better \\
\hline 5 & Wizutani & 1999 & 47 & W & $\begin{array}{l}\text { W-L,I+lla } \\
\text { type }\end{array}$ & $\begin{array}{l}\text { Distal } \\
\text { gastrectomy }\end{array}$ & better \\
\hline 6 & Our & 2010 & 71 & W & L-W,3type & $\begin{array}{l}\text { Total } \\
\text { gastrectomy+D2 }\end{array}$ & better \\
\hline
\end{tabular}

\section{Consent}

Written informed consent was obtained from the patient for publication of this case report and accompanying images.A copy of the written consent is available for review by the Editor-in-Chief of this journal.

\section{Author details}

'Department of Surgery, 4-6-1 Noishiki, Gifu City 500-8717, Japan.

2Department of Pathology, 4-6-1 Noishiki, Gifu City 500-8717, Japan.

\section{Authors' contributions}

$\mathrm{NN}$ and $\mathrm{CT}$ took part in the operation. TN,MK and KK performed the literature seach and drafted the manuscript for submission. HI performed histological examination and provided photomicrographs. All authors read and approved the final manuscript.

\section{Competing interests}

The authors declare that they have no competing interests.

Received: 18 July 2011 Accepted: 6 December 2011

Published: 6 December 2011

\section{References}

1. Boerhaave's Atroicis,descrips,morbid histroria: The first translation of the classic case report of rupture of the esophagus, with annotation. Bull Med libr 1955, 43:217-240.

2. Yoshida T: Guhatuseisyokudouharetsu no 1rei(in Japanese). Kaigunikaishi 1935, 24:97-98.

3. Kijima M, Aoki T, Nagao F: Experiences in the diagnosis and treatment of spontaneous rapture of the esophagus. A case of rapture concomitant with a gastric cancer -with a review of preexisting proemetic factors reported in japan-1987-Tokyo Jikeikai Medical J 1987, 102:1483-1987.

4. Abot OA, Mansour KA, Longan WD, et al: Atraumatic so-called "spontaneous"rupture of esophagus,a review of 47 personal cases with commnts on new method of surgical therapy. I Thorac Cardiovasc Surg 1970, 59:67-83.

5. Fukushima J, Nabeya K, Hanaoka T, et al: Hozontekikaryou de tiryoushita tokuhatuseisyokudouharetsu no 1rei(in Japanese). Kyurin I kaishi 1988, 19:455-460.

6. De Schipper JP, Pull ter Ginne AF, Oostvogel HJ, et al: Spontaneus rupture of the oesopagus:Boerhaave's syndrome in 2008.Literature review and treatment algorithm. Dig Surg 2009, 26(1):1-6

7. Landen S, El Nakadi I: Minimally inavasive approach to Boerhaave's syndrome:a pilot study of three cases. Surg Endosc 2002, 16(9):1354-1357.

8. Lawrence DR, Ohri SK, Moxon RE, et al: primary esophageal repair for Boerhaave's syndrome. Ann Thorac Surg 1999, 67(3):818-820.
9. Fiscon V, porrale $G$, Friqo $F$, et al: Spontaneous rupture of middle thoracic esophagus:thoracoscopisc treatment. Surg Endosc 2010, 24(11):2900-2902.

10. Teh E, Edwards J, Duffy J, et al: Boerhaave's syndorome:a review of management and outcome:Interract Cardiovasc Tharac Surg. 2007, 6(5):640-643.

11. Yoshida K, Ide H, Yamana, et al: Igan ni heipatushita tokhatuseisyokudouharetsu no 1tikenrei(in Japanese). Geka 1981, 8:875-879.

12. Emoto k, Nomiura T, Takahashi T, et al: A case of spontaneous rapture of the esophagus associated with an early gastric cancer. J of Transportation Med 1996, 50:175-178.

13. Itano S, Terada N, Hashimoto O, et al: Igan saitoinshi toshite hassyoushita tokuhatuseisyokudouharetsu no 1rei(in Japanese). Ringeka 1992. 53:1619-1623.

14. Kaneshiro $E$, Hanatani $Y$, Miyoshi $H$, et al: A case of spotaneuos rupture of the esophagus combined with gastric cancer. Teikyo Med J 1999, 22:363-368.

doi:10.1186/1477-7819-9-161

Cite this article as: Matsuhashi et al:: A patient with spontaneous rupture of the esophagus and concomitant gastric cancer whose life was saved: case of report and review of the literature in Japan. World Journal of Surgical Oncology 2011 9:161.

\section{Submit your next manuscript to BioMed Central and take full advantage of:}

- Convenient online submission

- Thorough peer review

- No space constraints or color figure charges

- Immediate publication on acceptance

- Inclusion in PubMed, CAS, Scopus and Google Scholar

- Research which is freely available for redistribution 